\title{
COMUNICAÇÃO
}

\section{ANALISE COMPARATIVA DA ORGANIZAÇÃO E METODOLOGIA DA SELEÇÃO CLONAL DA VIDEIRA NA FRANÇA E BRASIL ${ }^{1}$}

\author{
Clone selection methods for grapevine in France
}

\author{
Murillo de Albuquerque Regina
}

\section{RESUMO}

A origem policlonal da videira, associando-se sua sensibilidade à ocorrência de mutações somáticas espontâneas, faz com que exista uma grande variabilidade genética no interior de uma mesma cultivar dessa espécie, permitindo, por meio da seleção clonal, a obtenção de descendências que atendam aos objetivos específicos de produção, como produtividade e qualidade. Em razão da ocorrência generalizada de viroses na maioria dos vinhedos, a seleção clonal da videira é obrigatoriamente genética e sanitária, devendo obedecer a um certo número de etapas para que os clones selecionados possam atender aos requisitos qualitativos desejados. Na França, o programa de seleção clonal da videira data dos anos 60 , e já permitiu a obtenção de centenas de clones de cultivares porta-enxerto e cultivares de vinho e mesa. Com este trabalho objetivou-se ilustrar as diferentes etapas e organização da seleção clonal da videira na França.

Termos para Indexação: Variabilidade genética, viroses, certificação, Vitis sp.

\section{ABSTRACT}

The polyclone origin of grapevine has been associated with the high occurrence of somatic mutations. Most part of these mutations are spontaneous and are responsible for most of the genetic variability inside a variety of this species. The large genetic variability found in grapevine has allowed grape breeders to obtain new varieties with better agronomic traits only by clone selection. However, due to the virus occurrence, the clone selection has been used also to eliminate plant pathogens, as a routine procedure. The selection process of plants without virus follows a severe set of rules where several steps are developed before the new clone is obtained. The program of clone selection in France, has been developed since the 60's decade and has been responsible for the creation of hundreds of varieties of rootstocks, table grapes and wine grapes. This work has as main objective, make a report about the organization of the several stages of clone selection in France.

Index Terms: Genetic variability, virus, certification, Vitis sp.

(Recebido para publicação em 31 de julho de 2001 e aprovado em 6 de agosto de 2002)

$\mathrm{Na}$ França, a seleção clonal da videira iniciouse em 1960, com o Institut National de Recherche Agronomique - INRA, com o objetivo de colocar à disposição dos viticultores um material vegetativo mais sadio e, ao mesmo tempo, apresentar melhores características culturais e de produção (BOUBALS, 1996; BOUQUET, 2000; BOIDRON, 2000). A partir de 1962, com a criação do ENTAV (Etablissement National Technique pour l'Amélioration de la Viticulture - Estabelecimento Nacional Técnico para Melhoramento da Viticultura), então ANTAV (Association Nationale Technique pour l'Amélioration de la Viticulture - Associação Nacional Técnica para Melhoramento da Viticultura), os trabalhos de seleção naquele país passaram a ser coordenados de forma conjunta pelo ENTAV e INRA (Institut National de la Recherche Agronomique
- Instituto Nacional de Pesquisa Agronômica) (ONIVINS, 1996a).

A seleção clonal da videira é, ao mesmo tempo, genética e sanitária, e, por princípio, baseia-se na definição do clone, que segundo a OIV (Office International de la Vigne et du Vin - Ofício Internacional da Videira e do Vinho) é: "A descendência vegetativa de uma única planta escolhida por sua identidade indiscutível, seus caracteres fenotípicos e seu estado sanitário". (ENTAV, 1995; ONIVINS, 1996b; GRENAN et al., 1998).

Inicialmente a seleção clonal na França orientava para a escolha de clones mais produtivos, com objetivo de satisfazer à demanda elevada de vinho, e livres da degenerescência infecciosa (identificada posteriormente como a virose do entrenó curto), que afetava inúmeros vinhedos. Uma primeira geração de clones

\footnotetext{
1. Extraído do relatório de pós-doutorado do autor.

2. Engenheiro Agrônomo, DsC. - Pesquisador/EPAMIG - Avenida Santa Cruz, 500 - Caixa Postal 33-37780-000 - Caldas, MG. murillo@epamigcaldas.gov.br - Bolsista CNPq.
} 
sadios e mais férteis, selecionada entre as décadas de 70 e 80 , permitiu atingir os objetivos de aumento da produtividade e melhoria da sanidade dos vinhedos, permitindo, em determinadas regiões, a obtenção de rendimentos próximos a 11 toneladas. $\mathrm{ha}^{-1}$, com bons índices de maturação (HUGLIN e SCHNEIDER, 1998; BOIDRON, 2000).

Posteriormente, as mudanças registradas no consumo do vinho, particularmente com a tendência de redução do consumo per capita ("beber menos, mas beber melhor"), aliadas à reestruturação qualitativa de alguns vinhedos franceses, particularmente os situados na região mediterrânea, e ainda ao aumento da concorrência externa com novos países vitícolas, levaram a uma reorientação da seleção clonal, que passou a valorizar a identificação de clones à produção moderada e com forte potencial qualitativo. Dessa forma, os clones de uma mesma variedade de videira atualmente são reagrupados em grupos de potencial produtivo, sendo grupo A (qualitativo e pouco produtivo); grupo $\mathrm{B}$ (intermediário) ao $\mathrm{C}$ (produtivo), além dos clones com comportamento irregular, classificados no grupo D (ENTAV, 1995). Ao mesmo tempo, pôde-se constatar uma grande evolução da seleção sanitária, devido ao aumento dos conhecimentos sobre virologia e epidemiologia. Essa evolução permitiu que a seleção passasse da simples avaliação visual da ocorrência das viroses, até as indexagens em plantas indicadoras, a mais recentemente às avaliações por testes serológicos (ONIVINS, 1996a; WALTER, 1996). Assim, se no início da seleção sanitária orientava-se exclusivamente ao entrenó curto, e depois ao enrolamento, atualmente já são diagnosticadas seis viroses para as cultivares Vitis vinifera e oito para os porta-enxertos (WALTER, 1996, 1997a, 1997b).

Mais recentemente, e devido à pressão de redução da diversidade genética das principais cultivares de videira causada por uma seleção clonal muito intensa, os selecionadores têm orientado também seus trabalhos para a constituição dos Conservatórios Nacionais de clones, onde se busca conservar toda a variabilidade genética detectada dentro de uma mesma variedade (AUDEGUIN et al., 1998).

Os quarenta anos de seleção clonal na França permitiram a seleção e registro de centenas de clones, divididos nas seguintes categorias:

- Cultivares de vinho: 700 clones credenciados para 135 cultivares autorizadas na França;
- Cultivares de mesa: 75 clones credenciados para 12 cultivares autorizadas;

- Cultivares Porta-enxertos: 160 clones credenciados para 24 cultivares autorizadas.

Desse total, $7 \%$ dos clones são classificados no grupo A; $34 \%$, no grupo B; $18 \%$, no grupo C e $1 \%$ no grupo D. Os $40 \%$ restantes ainda não foram julgados (ENTAV, 1995).

Princípios e Metodologia da Seleção Clonal como já foi mencionado, a seleção clonal baseia-se na seleção genética e sanitária, buscando fornecer aos viticultores material de multiplicação sadio e com características culturais e de produção compatíveis com o destino da produção. Para o caso das cultivares de Vitis vinifera, ela supõe que o cultivo prolongado de uma determinada variedade origina uma variabilidade dos indivíduos. Essa variabilidade pode ter diferentes causas, tais como:

- origem policlonal natural (origem de seedlings distintos)

- mutações somáticas

- retorno ao estado juvenil

- presença de viroses desconhecidas e não-detectáveis

Essas diferenças genéticas podem manifestar-se sobre diferentes aspectos, como caracteres morfológicos, aspectos fenológicos, vigor, potencial de produção e qualidade.

No caso específico dos porta-enxertos, a seleção clonal é apenas sanitária em razão de suas origens recentes e monoclonais (CORDEAU, 1998).

Prospecão - trata-se da primeira etapa da seleção clonal. Busca-se a identificação no vinhedo de plantas com identidade varietal bem definida, sem sintomas de viroses e com potencial de produção ou fertilidade dentro dos objetivos estabelecidos para cada programa de seleção. Normalmente as prospeções são efetuadas em parcelas com mais de 25 anos de idade, e de preferência em regiões de cultura ainda pouco visitadas, onde as chances de ocorrência de variação são maiores. Nessa etapa, são necessários bons conhecimentos em ampelografia e virologia. Com relação às viroses, normalmente são recomendadas visitas em épocas diferentes nas mesmas parcelas, sendo no início do período vegetativo (sintomas do entrenó curto) e no final (enrolamento). As prospeções duram normalmente de um a dois anos na mesma parcela, e as plantas escolhidas são marcadas, e as suas estacas, recuperadas no período de repouso vegetativo, por ocasião da poda (WALTER, 1996; AUDEGUIN et al., 1999). 
Estudo Sanitário dos Clones - as estacas assim coletadas passam por uma primeira análise sanitária com teste ELISA, para as viroses do entrenó curto e enrolamento. Em caso de reação positiva para quaisquer uma dessas viroses, os clones são eliminados imediatamente. Em caso de reação negativa, o material é introduzido em Centros de Seleção (ENTAV/INRA) e passa a ser representado por uma única planta, normalmente cultivada em vasos. Em seguida, esse material passará pelos testes sanitários de indexagem em plantas indicadoras durante 2 a 3 anos. Ocorrendo a manifestação de viroses durante as indexagens, o clone será eliminado, ou, em casos especiais em que os clones possuem um interesse particular em multiplicação, tratado por termoterapia ou microenxertia (ENTAV, 1995; WALTER, 1996). Os clones sadios são transferidos para conservatórios (solo arenoso isento de nematóides e de outros vetores) onde são representados por 10 plantas - Material Inicial. Para o registro de um novo clone, ao mesmo tempo dos testes sanitários, são avaliados os potenciais de produção e qualidade dos clones por meio de diferentes etapas de competição. Assim, o registro de um novo clone dependerá de sua pureza sanitária e do interesse agronômico que ele apresenta. Uma vez credenciados, eles podem ser pré-multiplicados - Material de Base - por instituições publicas ou privadas credenciadas para esse fim, para, enfim, serem multiplicados pelos viveiristas - Material Certificado. Os novos clones mantidos em conservatórios deverão sofrer controles periódicos por teste ELISA para as principais viroses.

As viroses obrigatoriamente testadas durante a seleção sanitária são:

Produtoras (Vitis vinifera) - Entrenó curto, Enrolamento, Marbrure ou Fleck, Lenho rugoso, Caneluras sob Rupestris e Kober 5BB;

Porta-enxertos - Entrenó curto, Enrolamento, Marbrure ou Fleck, Lenho rugoso, Caneluras sob Rupestris e Kober 5BB, Mosaico das nervuras e Necrose das nervuras.

É importante ainda ressaltar que, para fins de registro de um novo clone, só os resultados das indexagens biológicas em plantas indicadoras são considerados. Os testes ELISA são considerados como uma técnica de verificação complementar (ENTAV, 1995; CORDEAU, 1998).

Estudo das Características Agronômicas e Enológicas dos Clones - realizado ao mesmo tempo que os testes de pureza sanitária, o estudo genético dos clones é imprescindível para verificação de suas potencialidades de produção e de qualidade. Se manifestar reação negativa nos testes ELISA para entrenó curto e enrolamento, o material introduzido nos Centros de Seleção é inicialmente introduzido em uma Coleção de Estudo. Trata-se de uma parcela experimental instalada obrigatoriamente na zona de cultura da cultivar em análise, e onde as características culturais dos clones candidatos ao registro serão avaliadas. Uma coleção de estudo deve possuir pelo menos dois clones já credenciados que servirão como testemunhas. Ela deve limitar-se a um máximo de 20 clones, e ser instalada com pelo menos três repetições de 3 a 5 plantas cada uma. No caso do número de clones ser limitado, deve-se aumentar as repetições para 6 e o número de plantas para 10. O dispositivo experimental deve ser o de blocos casualizados (AUDEGUIN et al., 1999).

As avaliações normalmente começam a partir do quarto ou quinto ano de instalação e devem prolongarse por pelo menos cinco anos. Durante essa etapa são avaliados:

- Fenologia: brotação e pintor;

- Peso de material de poda e índice de fertilidade

- Peso da colheita

- Qualidade da uva

- Características analíticas dos vinhos

- Qualidades organolépticas dos vinhos.

Essas informações podem eventualmente serem complementadas pelas seguintes observações complementares:

- Sensibilidade às doenças

- Desavinho e bagoinha

- Diferenças ampelográficas (porte, forma das folhas)

- Compacidade, tamanho e forma dos cachos

- Tamanho e forma das bagas.

Uma vez credenciados pelo CTPS (Comitê Técnico Permanente de Seleção), e antes de serem recomendados para uma determinada região, os clones devem ser introduzidos em Parcelas de Comportamento, que possuem o objetivo de estudar e comparar o comportamento dos clones já credenciados em uma determinada situação de cultivo. Ela compara as características, organolépticas e tecnológicas dos clones em função dos fatores do meio e das condições de produção de cada região estudada, e serve para orientação dos viticultores sobre quais clones escolher para uma determinada região vitícola.

Ciênc. agrotec., Lavras, v. 28, n. 1, p. 206-212, jan./fev., 2004 
As parcelas de comportamento devem compreender no máximo 15 clones, sendo pelo menos dois já credenciados e de utilização corrente dentro da região onde será instalada a parcela. A instalação no campo deve seguir um dispositivo experimental em blocos casualizados, com pelo menos 6 repetições e 10 plantas por parcela. A densidade de plantio e a forma de condução devem obedecer às normas usuais da região. $\mathrm{O}$ número de plantas deve ser previsto de forma a permitir a microvinificação de pelo menos 40 litros de vinho por clone.

As avaliações devem se iniciar a partir do $4^{\circ}$ ou $5^{\circ}$ ano de plantio e se estender por pelo menos cinco anos. Os parâmetros avaliados são os mesmos descritos para a Coleção de Estudo (AUDEGUIN et al., 1999).

Finalmente, o esquema da seleção clonal adotado na França prevê também a instalação dos Conservatórios Nacionais de Clones. Esses conservatórios são montados com os objetivo de resguardar o patrimônio genético existente no interior de cada cultivar, buscando conservar o maior número possíveis de clones identificados para uma mesma variedade (AUDEGUIN et al., 1998).

A instalação dos Conservatórios de clones é mais recente, e deve-se à preocupação com a erosão genética existente dentro da espécie $V$. vinifera na França, que ocorreu recentemente devido à redução do número de cultivares empregadas e ao cultivo intensivo de um número reduzido de clones para cada cultivar.

Os Conservatórios devem ser instalados em regiões representativas do cultivo para cada cultivar e responder às mesmas exigências sanitárias atribuídas aos matrizeiros, visando a manter o bom estado sanitário dos clones. Em seus aspectos práticos, os Conservatórios de Clones obedecem a dispositivos experimentais mais simples, limitando-se a um número de 5 a 10 plantas/clone, e à repetição, no interior da parcela, de apenas um clone de emprego generalizado e de características agronômicas bem conhecidas. Os testes sanitários serão realizados regularmente em cada planta, pelos testes ELISA para as viroses do entrenó curto e enrolamento. Os conservatórios podem ser instalados em propriedades particulares ou em Instituições públicas, que apresentem como garantia mínima a boa manutenção e a perenidade de acompanhamento das parcelas (AUDEGUIN et al., 1998).

A manutenção do potencial genético e sanitário dos clones selecionados é efetuada pelo ENTAV, que lança mão de todos os recursos atuais da biotecnologia e biologia molecular, como técnicas de PCR para iden- tificação de parasitas, como o da "Flavescence dorée", ou ainda para os estudos de identificação varietal e clonal por microsatélite. Esses avanços contribuem para a manutenção de alto padrão de qualidade dos clones selecionados.

No Brasil, apesar de já existirem vários clones sanitários selecionados para porta-enxertos e cultivares de videira, ainda não existe um protocolo oficial específico que regulamente as normas a serem seguidas nas diferentes etapas da seleção clonal. Nem tampouco os clones selecionados são registrados e protegidos. Tal situação deve-se, provavelmente a pouca expressão da área cultivada com videiras no País (aproximadamente 60 mil hectares), mas principalmente, à introdução relativamente recente da videira em nossas condições. Essa razão explicaria o fato de que a maior parte dos clones selecionados pelas instituições de pesquisa atendam principalmente aos critérios de seleção sanitária e não ao da genética, uma vez que a pressão de geração espontânea de novos clones por mutação somática ainda é relativamente baixa e limitada pelo pouco tempo de cultivo das principais cultivares em nosso meio. Exceções sejam feitas às mutações já identificadas, multiplicadas e cultivadas dos mutantes espontâneos de Niágara Branca (Niágara rosada) e de Itália (Rubi, Benitaka, e Brasil).

Para o Estado de Santa Catarina, Silva (2002) cita que, dentro do Programa de Certificação de mudas de videira, já em vigor para aquele Estado, as plantas originadas de seleção clonal devem ser mantidas em casa-de-vegetação e in vitro, e que os testes para verificação de identidade varietal, bem como de pureza sanitária, devem obedecer aos mesmos protocolos exigidos na França para os teste ELISA (Enzyme Linked Immuno Sorbent Assay), e de amplificação e caracterização do DNA por técnicas moleculares. Nesse caso, essas análises seriam executadas pelos laboratórios da Universidade Federal de Santa Catarina - UFSC e da Empresa de Pesquisa Agropecuária e Extensão Rural de Santa Catarina - EPAGRI. O controle sanitário para as viroses dos clones selecionados para matrizes básicas deve ser realizado de dois em dois anos, e o das plantas, certificadas a cada 5 anos. As amostragens de folhas (período vegetativo) e sarmentos (período de repouso) devem ser feitas em pelo menos $5 \%$ da área ou número de plantas matrizes. As plantas matrizes certificadas devem ser renovadas aos dez anos. 
A título comparativo, ressalta-se como uma das principais diferenças entre os sistemas propostos nos dois países, no que se diz respeito à certificação do material, o fato de que, na França, os testes sorológicos de monitoramento de viroses devem obrigatoriamente ser completados com as indexagens biológicas em plantas indicadoras quando da apresentação de um novo clone para registro. Essa exigência, apesar de aumentar o tempo necessário à obtenção de um novo clone, permite maior segurança com relação às doenças viróticas.

Seria interessante que a evolução da seleção clonal para a videira no Brasil passasse pela defini- ção oficial dos critérios a serem adotados em suas diferentes etapas, a fim de que os clones obtidos possam ser homologados no Serviço Nacional de Proteção de Cultivares, e que as Instituições envolvidas na sua obtenção possam ser remuneradas quando da sua multiplicação. Tal situação possibilitaria ao setor vitícola a exploração de clones nacionais selecionados para o nosso meio e, ao mesmo tempo, a retro-alimentação dos programas de seleção.

Nas Figuras 1 e 2 são ilustrados os esquemas adotados para a seleção genética e sanitária na França.

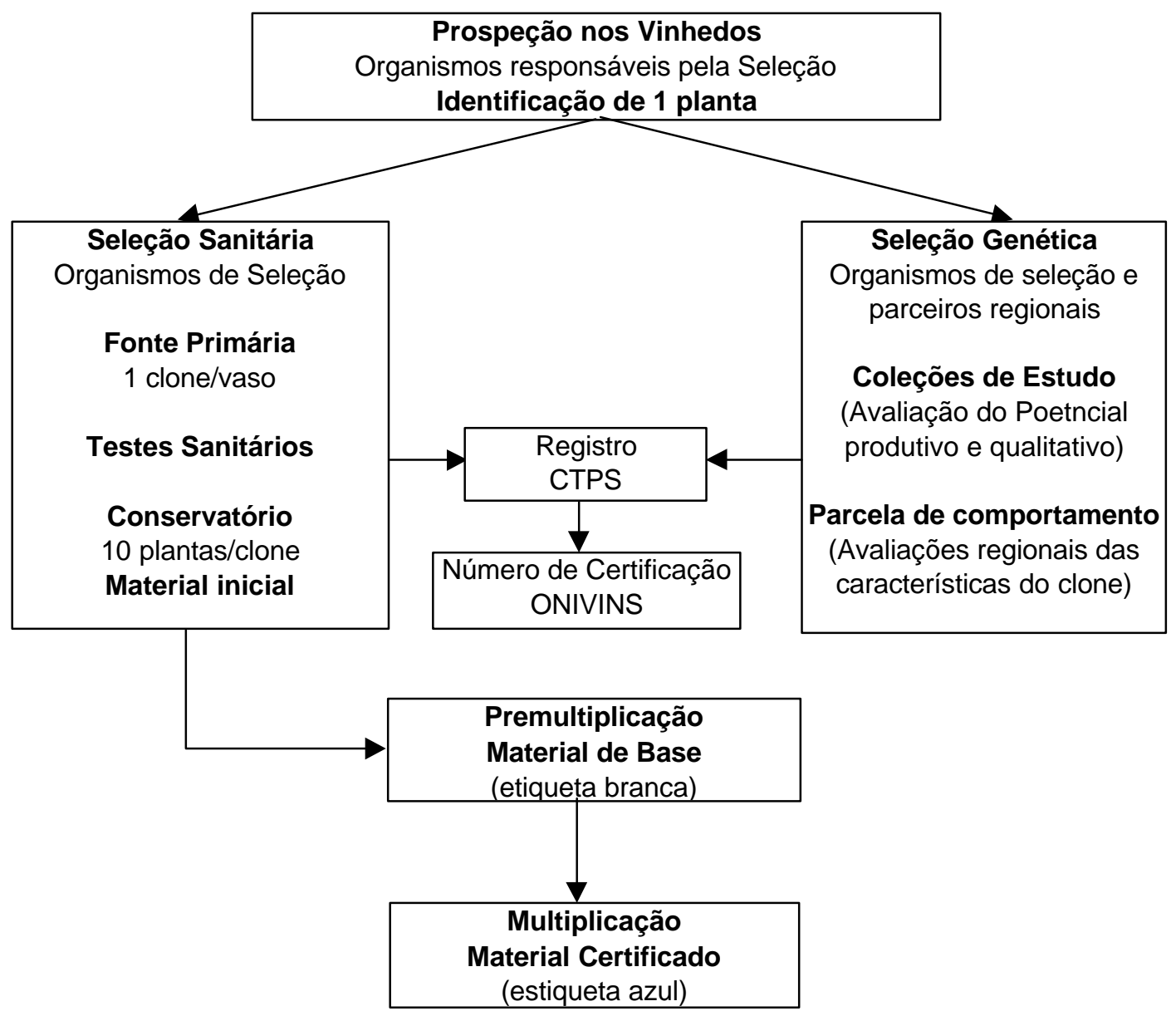

FIGURA 1 - Esquema da seleção clonal na França (ENTAV, 1995). 


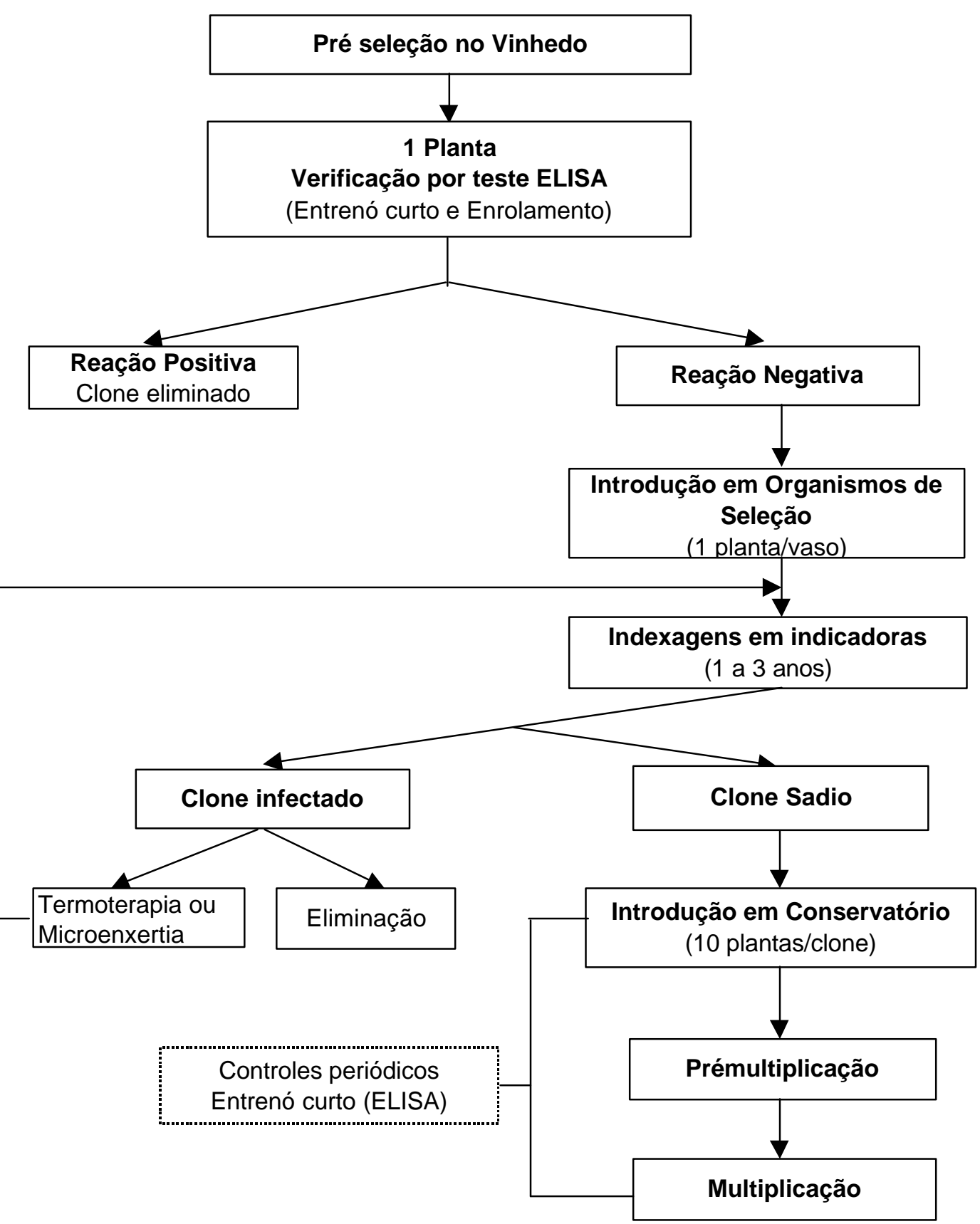

FIGURA 2 - Esquema da seleção sanitária na França (ENTAV, 1995). 


\section{AGRADECIMENTOS}

Ao CNPq, pela concessão da bolsa de estudos, ao ENTAV, pelo suporte técnico e ao pesquisador da EPAMIG Geraldo Magela de Almeida Cançado, pela colaboração na redação do trabalho.

\section{REFERENCIAS BIBLIOGRÁFICAS}

AUDEGUIN, L.; BOIDRON, R.; BLOY, P.; GRENAN, S.; LECLAIR, P.; BOURSIQUOT, J. M. L'expérimentation des clones de Vigne en France: etat des lieux, méthodologie et perspectives. Progrès Agricole et Viticole, Année, v. 116, n. 22, p. 486-491, 1999.

AUDEGUIN, L.; BOIDRON, R.; LECLAIR, P. H.; BOURSIQUOT, J. M. Les conservatoires de clones de cépages de cuve en France: etat des lieux, méthodologie e perspectives. Progès Agricole et Viticole, Année, v. 115 , n. 23, p. 503-514, 1998.

BOIDRON, R. Evolution de l'assortiment varietal et clonal : objectifs et méthodes de selection. Progés Agricole et Viticole, Année, v. 117, n. 5, p. 111-114, 2000.

BOUBALS, D. Le problème actuel de la sélection clonale, sanitaire et génétique de la vigne. Progrès Agricole et Viticole, Année, v. 113, n. 7, p. 163-164, 1996.

BOUQUET, A. La création variétale à l'INRA de 1950 a 1999: objectifs, méthodes, resultats: perspectives pour le XXI ${ }^{\text {ème }}$ siècle. Progrès Agricole et Viticole, Année, v. 117, n. 5, p. 114-118, 2000.

CORDEAU, J. Création d'un vignoble: greffage de la vigne et porte-greffes: elimination des maladies à virus. Bordeaux: Féret, 1998. 182 p.
ENTAV. Catalogue des variétés et clones de vigne cultivés en France. Grau du Roi, 1995. 357 p.

GRENAN, S.; BOIDRON, R.; BONNET, A. Bilan et réflexions sur 35 années de sélection sanitaire en France. Progrès Agricole et Viticole, Année, v. 115, n. 19, p. 406-414, 1998.

HUGLIN, P.; SCHNEIDER, C. Biologie et écologie de la vigne. Paris: Lavoisier Tec \& Doc., 1998. 370 p.

ONIVINS. La certification des plants de vigne. Progrès Agricole et Viticole, Année, v. 113, n. 7, p.158-160, 1996a.

ONIVINS. Viroses e la vigne et tests sanitaires. Progès Agricole et Viticole, Année, v. 113, n. 7, p. 161-162, 1996b.

SILVA, A. L. da. Programa de certificação de mudas de videira em Santa Catarina. In: Viticultura e enologia: atualizando conceitos. Caldas: EPAMIGFECD, 2002. p. 215-231.

WALTER, B. Effets des viroses sur la vigne et ses produits: I. généralités. Progès Agricole et Viticole, Année, v. 113, n. 22, p. 482-488, 1996.

WALTER, B. Effets des viroses sur la vigne et ses produits: III. l'enroulement et le complexe du bois strié. Progrès Agricole et Viticole, Année, v. 114, n. 4, p. 79-86, 1997a.

WALTER, B. Effets des viroses sur la vigne et ses produits: IV. virus et viroses divers: Marbrure, incompatibilités au greffage, énation, etc. Progrès Agricole et Viticole, Année, v. 114, n. 9, p. 199-204, 1997b. 